$16^{\text {th }}$ International Congress of Metrology, 12002 (2013)

DOI: $10.1051 /$ metrology/201312002

(C) Owned by the authors, published by EDP Sciences, 2013

\title{
A new Certified Reference Material of CETAMA: its certification approach
}

\author{
Corinne Rigaux ${ }^{1, \text { a }}$, Cédric Rivier ${ }^{1}$, Danièle Roudil ${ }^{1}$, Jean-Marc Adnet ${ }^{2}$, Catherine Eysseric ${ }^{2}$, Bruno Tufféry ${ }^{3}$, Alexandre \\ Ruas $^{3}$ \\ ${ }^{1}$ CEA, DEN, DRCP, CETAMA, F-30207 Bagnols-sur-Ceze, France \\ ${ }^{2}$ CEA, DEN, DRCP, F-30207 Bagnols-sur-Ceze, France \\ ${ }^{3}$ CEA, DEN, DRCP, SERA/LAMM/LAMMAN, F-30207 Bagnols-sur-Ceze, France
}

\begin{abstract}
To meet a need expressed by the French nuclear laboratories, the Commission for the Establishment of Analytical Methods (CETAMA) has provided a new reference material with high level in plutonium isotope ${ }^{242} \mathrm{Pu}$ and certified in isotopic ratio. Based on the ISO guide 34, the production of this material by LAMMAN laboratory (Metrology Laboratory of Nuclear Material) in CEA Marcoule has been made from a solution of plutonium nitrate enriched in ${ }^{242} \mathrm{Pu}$. The certification process has been undertaken by interlaboratory comparison in collaboration with five French and European laboratories. The method of mass spectrometry thermal ionization (TIMS) was recommended as the analytical technique for certification. The statistical processing of the data provided by the laboratories has been done by four different approaches. The "excessvariance" approach has proved to be the best to process these data. After determining certified values and their associated uncertainties, a certificate has been established for this new reference material ${ }^{242} \mathrm{Pu}$.
\end{abstract}

\section{Introduction}

Reference materials are essential tools for laboratories to evaluate and validate the performance of their testing procedures. By consensus, the definition of a reference material is described in the VIM [1]:

- Reference material (RM): material, sufficiently homogeneous and stable with reference to specified properties, which has been established to be fit for its intended use in measurement or in examination of nominal properties.

- Certified reference material (CRM): reference material, accompanied by documentation issued by an authoritative body and providing one or more specified property values with associated uncertainties and traceabilities, using valid procedures.

In the field of nuclear fuel cycle, these materials are used for the monitoring of nuclear materials, process controls, monitoring of the environment ... To meet the needs of the nuclear laboratories, the Commission for the Establishment of Analytical Methods (CETAMA) offers three types of certified reference materials:

- High purity materials certified in major elements $(\mathrm{U}, \mathrm{Pu}, \mathrm{Np})$. Their use is mainly for the calibration of chemical analysis instruments;

- Certified matrix materials intended primarily to assess performance characteristics (trueness, precision) of an analytical method. These matrices are representative of different steps of the fuel cycle (eg uranium ore concentrates);

- Materials certified in isotopic composition ( $\mathrm{U}, \mathrm{Pu})$ to calibrate isotopic analysis instruments (eg TIMS, ICPMS). They can also be used as isotopic "tracers", including monitoring of chemical reactions (eg extraction yield) but also as standards for analysis by isotope dilution.

As part of CETAMA working group "Plutonium" (WG3), French laboratories have expressed the need for a new plutonium reference material with high level in isotope ${ }^{242} \mathrm{Pu}$ and certified in isotopic ratio. This document presents the certification approach of this material, in the aim of making it available to the community of nuclear laboratories. The production and certification have been based on ISO guide 34 [2].

\section{Certification approach}

\subsection{Fabrication process}

By its physical characteristics (alpha and neutrons radiation) and radiotoxicity, manufacturing of ${ }^{242} \mathrm{Pu}$ solution requires a suitable and safety working environment such as a nuclear facility with glove boxes. The LAMMAN laboratory in the Atalante facility on the Marcoule site meets these requirements. It has the

\footnotetext{
${ }^{\mathrm{a}}$ Corresponding author: Corinne.rigaux@cea.fr
} 
technical skills of manufacturing, analytical testing, packaging and storage, already widely validated through the implementation of uranium and plutonium solutions for EQRAIN Proficiency Testing Schemes.

Figure 1. LAMMAN laboratory

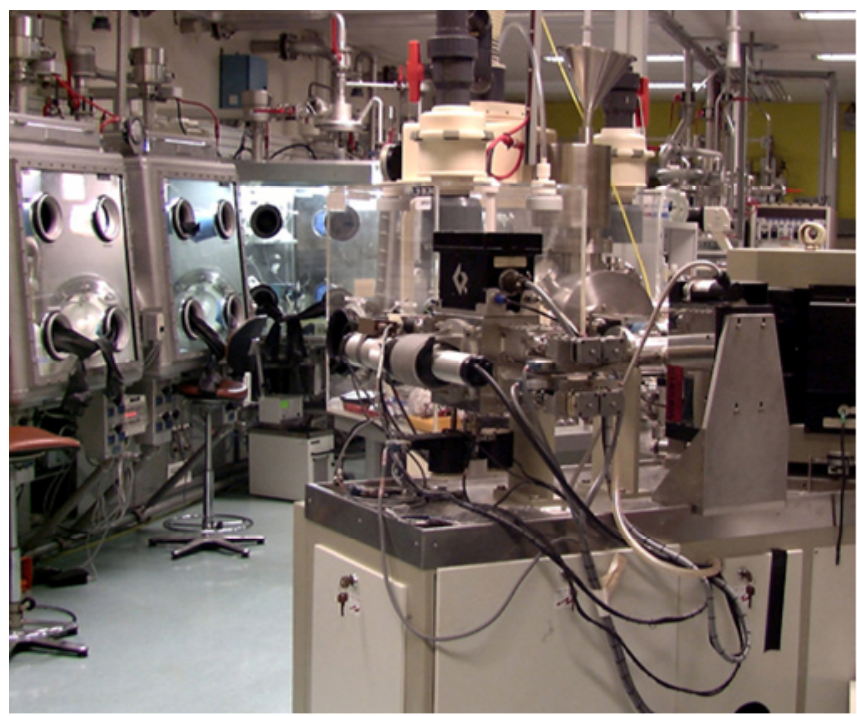

According to the specifications defined by CETAMA, the LAMMAN laboratory realized in April 2010 a production of two ${ }^{242} \mathrm{Pu}$ nitric solutions: $\mathrm{C} 1$ around $1 \mathrm{~g} . \mathrm{1}^{-1}$, and by dilution in a nitric acid a second solution $\mathrm{C} 2$ around $5 \mathrm{mg} . \mathrm{l}^{-1}$. The packaging of these two solutions was performed with laser sealing glass bulb.

Before sending the solution for the certification by interlaboratory comparison, a characterization of plutonium solutions was performed by the analysis laboratory LAMM in ATALANTE with a determination of the plutonium concentration and isotopic composition by TIMS/VG54.

\subsection{Interlaboratory Comparison organization}

With the aim to certify the material ${ }^{242} \mathrm{Pu}$ in isotopic composition, an interlaboratory comparison has been organized by CETAMA. Five laboratories (CEA, AREVA) including a European laboratory (Institute for Reference Materials and Measurements - IRMM) have participated in this interlaboratory comparison. One ampoule of $\mathrm{C} 2$ plutonium solution has been sent to each participating laboratory.

The identity of participants is kept confidential by assigning a specific code to each laboratory.

\subsubsection{Analysis technique}

The recommended analysis technique was Thermal Ionization Mass Spectrometry (TIMS) to measure the plutonium isotopic ratios [3-6]. The minimum number of sets was five independent measurements under repeatability conditions. The laboratories had also to provide their expended uncertainty associated with their mean value. Finally the number of reported measurement was between 1 to 5 by laboratory.
The measurement processes by TIMS technique implemented by the participating laboratories are similar, including sample preparation (purification by ionexchange resin). However, some differences are noted about the amount of material deposited on the rhenium filaments (from $50 \mathrm{ng}$ to $1 \mu \mathrm{g}$ ) and the nature of the reference standard used (IRMM-290, MP2, internal standard).

\subsubsection{Homogeneity test}

The homogeneity assessment of reference solutions has been studied. The property values being isotopic ratios of a same element, the homogeneity test is not an issue. Indeed, the isotopes of an element have the same chemical behavior, therefore inhomogeneity is not supposed to have an impact on the certified values.

\subsubsection{Stability test}

During this interlaboratory comparison, the participating laboratories have realized their isotopic analysis at different dates: from May 2010 to August 2011. Through the statistical process, no difference has been observed during around 1 year. The chemical stability study approach is based on our knowledge and lesson learned from the nitric reference solution fabrication of actinide elements over the last 25 years.

The gas production by alpha radiolysis phenomena is also studied in order to measure the potential impact over time on theses vials: the safety of their storage, concentration and acidity evolution. That is why the stability assessment must be confirmed over a longer period and at different times: 2 years, 5 years.

Currently this study is still in progress. But as for homogeneity, stability is not a real issue for reference materials certified in isotopic ratios.

\subsubsection{Considered data}

In the aim to process all data equivalently, the data have been updated at the date of 31 December 2011.

The standard measurement uncertainties provided by the laboratories have not changed significantly. A calculation of the ${ }^{241} \mathrm{Pu}$ isotope with the shortest half-life has been used to validate this assumption.

During their analyses, some laboratories have met some analytical problems such as:

- A contamination in the analytical process has been identified for the laboratory 5 . Its values on 3 isotopes being so different from other laboratories, the members of CETAMA working group have decided not to take them into account in the determination of reference values.

- The laboratory 4 was not able to measure isotope ${ }^{244} \mathrm{Pu}$. A mean value of this isotope has been determined from the values of three other laboratories and reassigned to the laboratory 4 . 
Finally the statistical process has been performed on the measurement results expressed by four participating laboratories and only 3 for ${ }^{244} \mathrm{Pu}$ values.

\section{Statistical process}

As part of this certification, the approach for statistical processing is based on the guide ISO 35 [7]. Four different statistical processes have been tested:

$$
\begin{array}{ll}
\text { - } \quad \text { "Robust statistics" approach } \\
\text { - } \quad \text { "Arithmetic mean" approach } \\
\text { - "Weighted mean" approach } \\
\text { - } \quad \text { "Excess variance" approach }
\end{array}
$$

These main approaches are developed below.

\section{1 "Robust statistics" approach}

\subsubsection{Calculation of the robust mean}

In this approach, the robust mean is based on the algorithm A of ISO 5725-5 standard [8]. It integrates all the results, including those considered outliers according to the criteria of a normal distribution.

\subsubsection{Calculation of the standard uncertainty of the robust mean}

The standard uncertainty of the robust mean is calculated from the equation below according to the ISO 13528 standard [9]:

$$
u_{\text {rob }}=\frac{1.25 . s^{*}}{\sqrt{p}}
$$

Where:

$u_{r o b}$ : Standard uncertainty of the robust mean

$S^{*}$ : Robust standard deviation of all laboratory results

$p$ : Number of participating laboratories.

This approach is based on an iterative process to minimize the influence of extreme values. However, the standard measurement uncertainties expressed by laboratories are not taken into account both in the calculation of the value assigned and in the calculation of its uncertainty.

\section{2 "Arithmetic mean" approach}

The Arithmetic mean approach [10] is based on the calculation of the arithmetic mean of laboratory results.

\subsubsection{Calculation of the mean by Arithmetic mean approach}

The mean $X_{\text {ref }}$ is calculated by the following equation:

$$
X_{\text {ref }}=\frac{\bar{X}_{1}+\bar{X}_{2}+\bar{X}_{3}+\bar{X}_{4}}{4}
$$

Where:

$\bar{X}$ : mean value of each laboratory

\subsubsection{Calculation of the standard measurement uncertainty by Arithmetic mean approach}

The standard measurement uncertainty by Arithmetic mean approach is calculated by following equation:

$$
u\left(X_{\text {réf }}\right)=\frac{\sqrt{\sum u^{2}\left(X_{i}\right)}}{n}
$$

Where:

$$
\begin{array}{ll}
n & : \text { Number of laboratory } \\
u\left(X_{i}\right): \text { Standard uncertainty of laboratory result }
\end{array}
$$

In this approach all laboratory results are taken into account without weight. The standard measurement uncertainties expressed by the laboratories are not taken into account in calculating the arithmetic mean of the assigned value. But they are taken in the calculation of the uncertainty of the assigned value.

\section{3 "Weighted mean" approach}

The approach called "weighted mean approach" in this document is based on the calculation of the weighted mean of laboratory results. This approach takes into account through a weighing factor, the standard measurement uncertainties expressed by the laboratories.

The weighing factor $w_{i}$ is calculated by the following equation:

$$
w_{i}=\frac{\frac{1}{u^{2}\left(X_{i}\right)}}{\sum_{j=1}^{p} \frac{1}{u^{2}\left(X_{j}\right)}}
$$

$u\left(X_{i}\right)$ : Standard uncertainty of laboratory result

\subsubsection{Calculation of the weighted mean}

The calculation of the mean uses the mean value of each laboratory weighted by the factor $w_{i}$ according to the following equation:

$$
X_{\text {ref }}=\sum w_{i} x_{i}
$$

\subsubsection{Calculation of the standard measurement uncertainty by weighted mean approach}

The calculation of the standard measurement uncertainty on the weighted mean takes the standard measurement uncertainty of each laboratory $u\left(X_{i}\right)$ weighted by the factor $w_{i}$ according to the following equation:

$$
u\left(X_{\text {ré } f}\right)=\sqrt{\sum w_{i}^{2} u^{2}}\left(x_{i}\right)
$$


However the laboratories must have an estimate of their measurement uncertainties by TIMS, the most accurate possible. And a biased laboratory result associated with a small uncertainty would lead to a biased certified value.

\section{4 "EXCESS variance" approach}

The Excess variance approach is based on the CCQM procedure (Comité Consultatif pour la Quantité de Matière) given in [11-12]. This approach uses a factor $w_{i}$ taking into account the standard measurement uncertainties of the laboratories and the spread $\lambda$ of the interlaboratory comparison results.

\subsubsection{Calculation of the weighted factor and the standard measurement uncertainty}

They are defined by the following equation:

$$
\widetilde{w}_{i}=\frac{\left(u_{i}^{2}+\lambda\right)^{-1}}{\sum_{j=1}^{p}\left(u_{j}^{2}+\lambda\right)^{-1}}
$$

Where $\lambda$ :

$$
\lambda=\max \left[0, \frac{\sum_{i=1}^{p} w_{i}\left(x_{i}-x_{G D}\right)^{2}-p+1}{W_{1}-W_{2} / W_{1}}\right]
$$

With $\mathrm{W}_{1}$ et $\mathrm{W}_{2}$ :

$$
W_{1}=\sum_{i=1}^{p} w_{i} \text { et } W_{2}=\sum_{i=1}^{p} w_{i}^{2}
$$

And

$$
x_{G D}=\frac{1}{W_{1}} \sum_{i=1}^{p} w_{i} x_{i}
$$

$\mathrm{p} \quad$ : number of participating laboratories

$w_{i}$ : calculated according to the equation described in the weighted mean approach

\section{Note:}

If $\lambda=0$, the standard measurement uncertainty is calculated according to the equation of the following weighted mean approach:

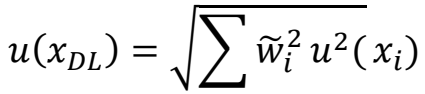

If $\lambda>0$, the standard measurement uncertainty is calculated using the following equation:

$$
u\left(x_{D L}\right)=\left[\sum_{i=1}^{p} \widetilde{w}_{i}^{2}\left(x_{i}-x_{D L}\right)^{2} /\left(1-\widetilde{w}_{i}\right)\right]^{1 / 2}
$$

\subsubsection{Calculation of the mean}

The weighted mean is calculated by the following equation:

$$
x_{D L}=\sum_{i=1}^{N} \widetilde{w}_{i} x_{i}
$$

With:

$x_{i}$ : Mean result provided by laboratory $\mathrm{i}$

$u_{i}$ : Standard measurement uncertainty

$\widetilde{w}_{i}:$ Weighted factor

\section{Summary and discussion}

For each plutonium isotopes $\left({ }^{238} \mathrm{Pu},{ }^{239} \mathrm{Pu},{ }^{240} \mathrm{Pu},{ }^{241} \mathrm{Pu}\right.$, ${ }^{242} \mathrm{Pu},{ }^{244} \mathrm{Pu}$ ), an isotopic ratio has been determined on ${ }^{\text {total }} \mathrm{Pu}$ and ${ }^{242} \mathrm{Pu}$. The data used come from the data of four selected laboratories apart from ${ }^{244} \mathrm{Pu}: 3$ results.

In this summary, the example chosen concerns the statistical approach on the isotope ratio ${ }^{242} \mathrm{Pu} /{ }^{\text {total }} \mathrm{Pu}$.

\subsection{Data analysis}

At first, the replicates of each laboratory with their mean and expanded measurement uncertainty (at $\mathrm{k}=2$ ) are showed in the table below.

Table 1. Data by laboratory

\begin{tabular}{|c|c|c|c|c|}
\cline { 2 - 5 } \multicolumn{1}{c|}{$\mathbf{n}\left({ }^{\mathbf{2 4 2}} \mathbf{P u}\right) / \mathbf{n}$ ( $\left.{ }^{\text {total }} \mathbf{P u}\right)$} & Lab 1 & Lab 2 & Lab 3 & Lab 4 \\
\hline Essai 1 & 98.54212 & 98.55006 & 98.57052 & 98.53618 \\
\hline Essai 2 & 98.54440 & 98.54950 & 98.55150 & \\
\hline Essai 3 & 98.54424 & 98.54904 & 98.55150 & \\
\hline Essai 4 & & 98.54912 & 98.55053 & \\
\hline Essai 5 & & 98.54646 & 98.55055 & \\
\hline Mean & 98.54359 & 98.5488 & 98.55 & 98.54 \\
\hline $\begin{array}{c}\text { Expanded measurement } \\
\text { uncertainty (k=2) }\end{array}$ & $\mathbf{0 . 0 0 0 7 1}$ & $\mathbf{0 . 0 0 3 5}$ & $\mathbf{0 . 1 1}$ & $\mathbf{0 . 9 9}$ \\
\hline
\end{tabular}

Figure 2. Graphical representation of data with their uncertainties by laboratory codes

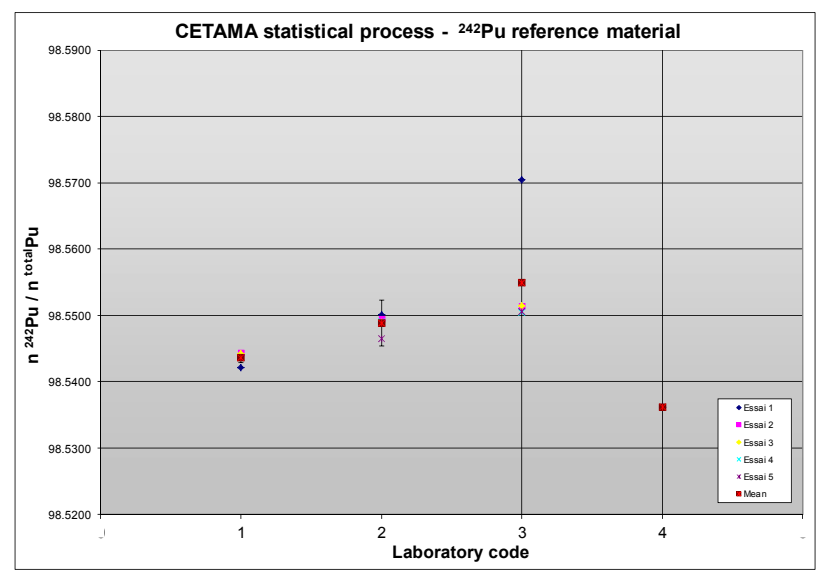

For each isotope, the results show a large difference between the measurements uncertainties provided by each laboratory. This difference can reach a factor of 100 . The need to weight the mean by the uncertainties of each laboratory proves imperative. 


\subsection{Statistical approaches}

The statistical process has been studied on four approaches: "Robust statistics" approach, "Arithmetic mean" approach, "weighted mean" approach, and "Excess variance" approach.

For each statistical approach and in our example with ${ }^{242} \mathrm{Pu}$ isotope, the mean of value assigned and its associated expanded measurement uncertainty (at $\mathrm{k}=2$ ) are specified in table below.

Table 2. Data by statistical approach

\begin{tabular}{|c|c|c|c|c|}
\hline $\mathrm{n}\left({ }^{242} \mathrm{Pu}\right) / \mathrm{n}\left({ }^{\text {total }} \mathrm{Pu}\right)$ & $\begin{array}{l}\text { Arithmetic Mean } \\
\text { approach }\end{array}$ & $\begin{array}{c}\text { Weighted Mean } \\
\text { approach }\end{array}$ & $\begin{array}{c}\text { Excess variance } \\
\text { approach }\end{array}$ & Robust statistics \\
\hline Mean & 98.55 & 98.54379 & 98.5459 & 98.5459 \\
\hline $\begin{array}{c}\text { Expanded measurement } \\
\text { uncertainty }(\mathrm{k}=2)\end{array}$ & 0.25 & 0.00070 & 0.0052 & 0.0090 \\
\hline
\end{tabular}

Figure 3. Graphical representation of statistical processing for the ${ }^{242} \mathrm{Pu}$ isotope

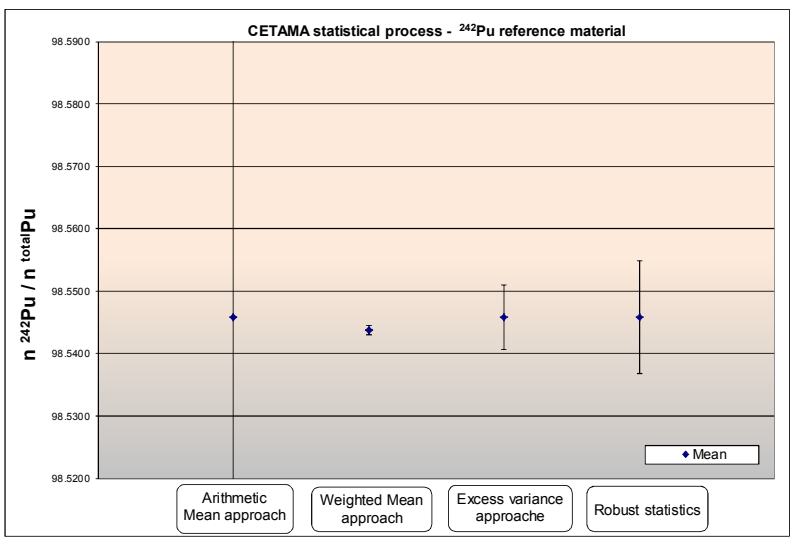

According to isotopes, some disparity in data and estimation of measurement uncertainties are observed.

In the "robust statistics" approach, all 14 data of isotope ${ }^{242} \mathrm{Pu}$ are taken into account. Extreme values are weighted in the calculation of the mean and standard deviation. However, the standard measurement uncertainties of the laboratories are not taken into account.

For the "Arithmetic mean" approach, the standard measurement uncertainties of the laboratories are taken into account for the calculation of the standard measurement uncertainty of the certified value. This is not the case for the mean calculation on certified value. Due to the low amount of data, statistical tests for outliers are impossible to implement. Moreover, this approach has a high sensitivity to outliers, the standard measurement uncertainty of the assigned value is greater than in the other approaches.

The "weighted mean" approach takes into account the standard measurement uncertainties of each laboratories in the calculation of the mean and the standard uncertainty of the assigned value. But a high sensitivity in case of under-estimation of uncertainties for one laboratory brings this approach to have a very low standard uncertainty of the reference value.

This is why the most relevant and successful statistical process in our study is the "Excess variance" which takes into account the measurement uncertainties of the laboratories and the spread of the results of all participants through a weighing factor.

Based on this approach, the certified values have been calculated. They are expressed as:

- Isotopic ratios relative to the total amount of plutonium: ${ }^{\text {xx }} \mathrm{Pu} /{ }^{\text {total }} \mathrm{Pu}$

- Isotopic ratios relative to the amount of plutonium ${ }^{242} \mathrm{Pu}:{ }^{\mathrm{xxx}} \mathrm{Pu} /{ }^{242} \mathrm{Pu}$

Table 3. Certified values in isotopic ratios ${ }^{x x x} \mathrm{Pu}{ }^{\text {fotal }} \mathrm{Pu}$

\begin{tabular}{|c|c|c|c|}
\hline \multicolumn{4}{|c|}{ Certified values (in atom \%) } \\
\hline $\mathrm{n}\left({ }^{238} \mathrm{Pu}\right) / \mathrm{n}(\mathrm{Pu})$ & $0.25373 \pm 0.00018$ & $\mathrm{n}\left({ }^{239} \mathrm{Pu}\right) / \mathrm{n}(\mathrm{Pu})$ & $0.2665 \pm 0.0016$ \\
\hline $\mathrm{n}\left({ }^{20} \mathrm{Pu}\right) / \mathrm{n}(\mathrm{Pu})$ & $0.56334 \pm 0.00030$ & $\mathrm{n}\left({ }^{241} \mathrm{Pu}\right) / \mathrm{n}(\mathrm{Pu})$ & $0.3348 \pm 0.0023$ \\
\hline $\mathrm{n}\left({ }^{242} \mathrm{Pu}\right) / \mathrm{n}(\mathrm{Pu})$ & $98.5459 \pm 0.0052$ & $\mathrm{n}\left({ }^{244} \mathrm{Pu}\right) / \mathrm{n}(\mathrm{Pu})$ & $0.03775 \pm 0.00011$ \\
\hline
\end{tabular}

Table 4. Certified values in isotopic ratios ${ }^{x x x} \mathrm{Pu}{ }^{242} \mathrm{Pu}$

\begin{tabular}{|c|c|c|c|}
\hline \multicolumn{4}{|c|}{ Certified values (in atom \%) } \\
\hline$n\left({ }^{238} \mathrm{Pu}\right) / \mathrm{n}\left({ }^{242} \mathrm{Pu}\right)$ & $0.25740 \pm 0.00041$ & $\mathrm{n}\left({ }^{239} \mathrm{Pu}\right) / \mathrm{n}\left({ }^{242} \mathrm{Pu}\right)$ & $0.2704 \pm 0.0017$ \\
\hline $\mathrm{n}\left({ }^{240} \mathrm{Pu}\right) / \mathrm{n}\left({ }^{242} \mathrm{Pu}\right)$ & $0.57166 \pm 0.00027$ & $\mathrm{n}\left({ }^{241} \mathrm{Pu}\right) / \mathrm{n}\left({ }^{242} \mathrm{Pu}\right)$ & $0.3392 \pm 0.0020$ \\
\hline & & $\mathrm{n}\left({ }^{244} \mathrm{Pu}\right) / \mathrm{n}\left({ }^{242} \mathrm{Pu}\right)$ & $0.03830 \pm 0.00011$ \\
\hline
\end{tabular}

The discrepancies in the uncertainty measurements provided by the laboratories can be explained by the methodologies used for the calibration of TIMS and by the number of replicates performed (up to 40 for some laboratories).

According to ISO 31 [13] guide this process has been finalized by establishing the certificate.

Figure 4. Certificate of ${ }^{242} \mathrm{Pu}$ reference material

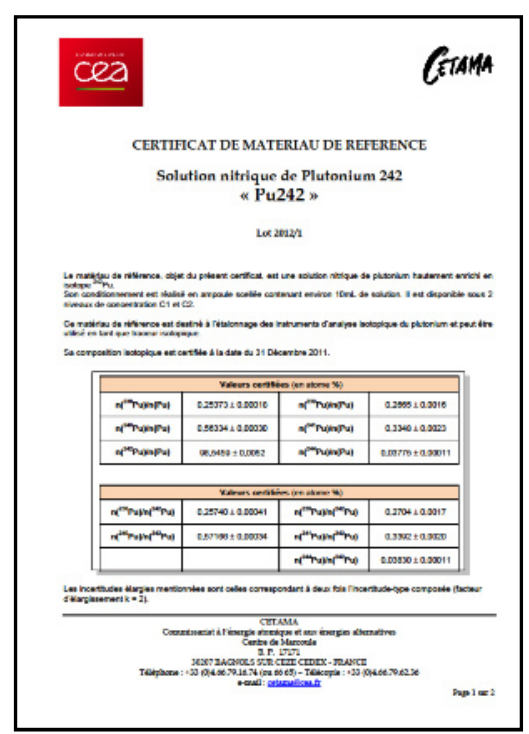

This new reference material ${ }^{242} \mathrm{Pu}$, certified in isotopic ratio with associated uncertainties is now available in the catalog CETAMA.

\section{Conclusion}

In the current context in the nuclear field, CETAMA decided to provide a new plutonium reference material with high level in ${ }^{242} \mathrm{Pu}$ and certified in isotopic ratio. 
An interlaboratory comparison with five European laboratories has been organized to certify this material. To measure the plutonium isotopic ratios, the analysis technique used by all participating laboratories was Mass Spectrometry Thermal Ionization TIMS.

Among four statistical approaches studied, a novel "Excess variance" statistical approach was chosen to determine the certified values and its associated measurement uncertainties. This technique uses a weighing factor taking into account the standard uncertainties of the laboratories and the dispersion of the results of all participants.

However, the stability assessment must be confirmed over a longer period. Currently the chemical and radiolysis field are still in progress.

In the future, new certified reference materials will be necessary for the nuclear laboratory needs. CETAMA has already planned other reference material productions with certification process by interlaboratory comparison such as a high purity metal plutonium reference material, an uranium ore concentrate matrix reference material "Feldspath".

\section{Acknowledgements}

For their participation in this interlaboratory comparison, CETAMA would like to thank the teams of five expert laboratories for the high quality of their analyses:

- A. Ruas from CEA/DEN/DRCP/SERA/LAMM

- H. Isnard from CEA/DEN/DCP/SECR/LANIE

- M. Aubert from CEA/DEN/DCP/SECR/LANIE

- JC. Hubinois from CEA/DAM/DMA/SRPU/LCA

- P. Knipiler from AREVA-Melox

- Y. Aregbe from European Commission-IRMM

- R. Jakopic from European Commission-IRMM

\section{References}

1. JCGM 200:2012, International vocabulary of metrology - Basic and general concepts and associated terms $-3^{\text {rd }}$ edition (2008)

2. FD ISO Guide 34, General requirements for the competence of reference material producers (2010)

3. S. Bürger, S.D. Balsley, S. Baumann, J. Berger, S.F. Boulyga, J.A. Cunnungham, S. Kappel, A. Koepf, J. Poths, Intern. J. Mass Spectrom. 311, 40-50 (2012)

4. S. Bürger, R.M. Essex, K.J. Mathew, S. Richter, R.B. Thomas, Intern. J. Mass Spectrom. 294, 65-76 (2010)

5. R. Jakopic, A. Verbruggen, R. Eykens, F. Kehoe, H. Kühn, Y. Kushigeta, U. Jacobsson, J. Bauwens, S. Richter, R. Wellum, Y. Aregbe, J. of Radioanal. and Nucl. Chem. 286, 449-454 (2010)

6. R. Jakopic, S. Richter, H. Kühn, Y. Aregbe, J. Anal. At. Spectrom. 25, 815-821 (2010)

7. FD ISO Guide 35, Reference materials - General and statistical principles for certification (2006)

8. NF ISO 5725-5, Application statistics - Accuracy (trueness and precision) of measurement methods and results - Part 5: alternative methods for the determination of the precision of a standard measurement methods (1998)

9. NF ISO 13528, Statistical methods for use in proficiency testing by interlaboratory comparisons (2005) 10. JCGM 100, Evaluation of measurement data -Guide to the expression of uncertainty in measurement (2008)

11. M. Cox, P. Harris and S. Ellison, CCQM Discussion document, 2011-04-01 (2011)

12. M. Cox, Metrologia 39, 589-595 (2002)

13. ISO Guide 31, Reference materials - Content of certificates and labels (2000) 